Article

\title{
In Vitro Anti-Wrinkle and Skin-Moisturizing Effects of Evening Primrose (Oenothera biennis) Sprout and Identification of Its Active Components
}

\author{
Tae Heon Kim ${ }^{1}$, Woo Jung Kim ${ }^{2}$, Soon Yeong Park ${ }^{3}$, Hoon Kim ${ }^{4, *}$ and Dae Kyun Chung ${ }^{4,5, *}$ \\ 1 Graduate School of Biotechnology and Institute of Life Science and Resources, Kyung Hee University, \\ Deogyeong-daero 1732, Giheung-gu, Yongin 17104, Korea; kimbob159@naver.com \\ 2 Biocenter, Gyeonggido Business and Science Accelerator, Gwanggyo-ro 147, Yeongtong-gu, \\ Suwon 16229, Korea; wj0504@gbsa.or.kr \\ 3 Dain Natural Co., Ltd., 130-33, Gasong-ro, Pungse-myeon, Dongnam-gu, Cheonan 31216, Korea; \\ rnd@dainnatural.com \\ 4 Skin-Biotechnology Center, Kyung Hee University, Gwanggyo-ro 147, Yeongtong-gu, Suwon 16229, Korea \\ 5 Graduate School of Biotechnology, Kyung Hee University, Deogyeong-daero 1732, Giheung-gu, \\ Yongin 17104, Korea \\ * Correspondence: hkim81@khu.ac.kr (H.K.); dkchung@khu.ac.kr (D.K.C.)
}

check for

updates

Citation: Kim, T.H.; Kim, W.J.; Park, S.Y.; Kim, H.; Chung, D.K. In Vitro Anti-Wrinkle and

Skin-Moisturizing Effects of Evening Primrose (Oenothera biennis) Sprout and Identification of Its Active

Components. Processes 2021, 9, 145. https://doi.org/10.3390/pr9010145

Received: 30 November 2020

Accepted: 10 January 2021

Published: 13 January 2021

Publisher's Note: MDPI stays neutral with regard to jurisdictional clai$\mathrm{ms}$ in published maps and institutional affiliations.

Copyright: (C) 2021 by the authors. Licensee MDPI, Basel, Switzerland. This article is an open access article distributed under the terms and conditions of the Creative Commons Attribution (CC BY) license (https:// creativecommons.org/licenses/by/ $4.0 /)$.

\begin{abstract}
The present study aimed to investigate the effect of Oenothera biennis sprout extract (OBSE) on skin-function improvement in an in vitro system and to identify its pharmaceutically active components. OBS-E showed antioxidant ability in radical scavenging and reducing power assays, significantly inhibited matrix metalloproteinases- 1 and -2 , and increased the production of type I collagen, indicating its anti-wrinkle activity. Furthermore, OBS-E significantly increased the level of hyaluronic acid (HA) and the expression of moisturizing genes, such as hyaluronic acid synthase 2 (HAS2) and aquaporin 3 (AQP3), indicating it is effective in enhancing skin hydration. Highperformance liquid chromatography (HPLC) and mass spectrometry (MS) analyses showed that OBS-E contained high levels of polyphenolic acids, such as gallic acid and ellagic acid, in addition to flavonoid glycosides, such as luteolin 7-glucuronide and quercetin 3-glucuronide. Our results suggest that these major phytochemicals are likely to play crucial roles in the expression of antioxidant, antiwrinkle, and moisturizing activities of OBS-E.
\end{abstract}

Keywords: Oenothera biennis; antioxidant; skin-improvement activity; tandem mass spectrometry; physiologically active ingredient

\section{Introduction}

The skin is the largest and one of the most important organs of the human body, providing a barrier that prevents the entry of hazardous substances and pathogens inside the body, while regulating temperature and controlling under- or over-hydration, maintaining essential chemicals and nutrients, and preventing the harmful effects of sunlight [1]. Apart from the maintenance of a healthy skin by the application of cosmetics (beautification from the outside), recent skincare interests include those directed toward achieving beautification from the inside, achieved by the oral administration of functional and medicinal substances [2]. The term cosmeceutical, coined by Albert Kligman in 1984, represents the blending of cosmetics and pharmaceuticals [3]. Since the beginning of the 21th century, many researchers and cosmeceutical developers have been attempting to find novel substances that have positive influences on human skin health when consumed orally. Consequently, several notable compounds, such as polyphenols isolated from green tea and cocoa, proanthocyanidin from grape seeds, silibinin from milk thistle seeds, resveratrol from grapes, blueberries, and raspberries, and isoflavonoids from soy beans have been reported in several studies [3]. 
Since ancient times, plants have been acknowledged as a major source of favorable materials for human life, and herbal plants, in particular, are now widely used as raw materials or extracts in various fields. Compared with synthetic materials, medicinal plants are generally recognized as safer and having fewer adverse effects. Therefore, they are becoming widely used in diverse fields, such as pharmacology, cosmetics, perfumery, nutraceuticals, beverages, and dyeing industries $[4,5]$. The genus Oenothera, known as evening primrose, contains approximately 145 species of herbaceous flowering plant [6]. This genus is generally recognized to have a wide range of medicinal properties, such as antioxidant [7,8], anti-inflammatory [9], anti-bacterial [10], anticancer [11,12], and antiobesity properties [8]. Oenothera biennis (OB), the most commonly known evening primroses worldwide, is a herbaceous weed native to the eastern US, but it can now be found in many other countries, such as Korea, Japan, Australia, Britain, France, and Hawaii [13]. The most well-studied biological activity of $\mathrm{OB}$ is its antioxidant activity $[7,14,15]$. Based on its antioxidant properties, Montserrat-de la Paz et al. [16] and Ma et al. [17] investigated the use of $\mathrm{OB}$ as an anti-inflammatory agent. Furthermore, Kwak et al. [8] reported the antiproliferative and antimicrobial efficacy of biological compounds isolated from the roots of OB. In another study, the potential use of seedcakes containing OB extract as a cosmetic ingredient was investigated by evaluating their antioxidant and anti-inflammatory activity in in vivo and ex vivo systems [18]. With respect to the bioactive ingredients in $\mathrm{OB}$, various phytochemicals, such as gallic acid, caffeic acid, epicatechin, coumaric acid, ferulic acid, rutin, and rosmarinic acid were identified and analyzed in the hydroalcoholic extract of OB [19]. In addition, Timoszuk et al. [20] investigated the biological activity depending on the chemical composition of OB in their review article, and Munir et al. [21] provided broad information on various pharmacological activities and phytoconstituents of the genus Oenothera in their comprehensive review article. However, most studies have specifically used seed, root, and stem tissues of $\mathrm{OB}$, rather than other tissues, including young leaves (sprouts). In the present study, we aimed to investigate the in vitro effect of Oenothera biennis sprout (OBS) on skin-function improvement using dermal fibroblasts and epithelial keratinocytes, and identify its pharmaceutically active components by conducting analytical experiments.

\section{Materials and Methods}

\subsection{Preparation of Oenothera biennis Sprout Extract (OBS-E)}

Fresh evening primrose sprouts harvested in the Gyeonggi province (Korea) in 2019 were used in this study (Supplementary Figure S1). Internal transcribed spacer (ITS) and National Center for Biotechnology Information (NCBI) database analyses showed that the DNA sequence of our evening primrose sprouts had a $100 \%$ correspondence with that of Oenothera biennis (MT610948.1) (Supplementary Figure S2 and Table S1). The fresh OBS was firstly dried in a heating oven (Daesan machinery, Hwaseong, Korea) at $40{ }^{\circ} \mathrm{C}$ to remove the moisture, and was ground using pulverizing machinery (Hankookmc Co., Ltd., Incheon, Korea) to obtain the OBS powder. The dried OBS was then extracted by stirring with seven volume of $50 \%(v / v)$ ethanolic water against the OBS for $24 \mathrm{~h}$ at room temperature (RT). The extract was filtered through a filtering cloth $(10 \mu \mathrm{m}$, FilterTech Co., Ltd., Daejeon, Korea) to remove non-soluble particles, and then evaporated using a rotary vacuum evaporator (Eyela, Tokyo, Japan). After drying in the heating oven at $70^{\circ} \mathrm{C}$ for $48 \mathrm{~h}$, the dried extract was powdered using pulverizing machinery to obtain the OBS extract (OBS-E) with a yield of $18.7 \%(w / w)$.

\subsection{Antioxidant Activities}

\subsubsection{Free Radical Scavenging Activity}

To measure the radical scavenging activities, we used two types of radical, 2,2'-azinobis (3-ethylbenzothiazoline-6-sulfonic acid) (ABTS; Sigma-Aldrich, St. Louis, MO, USA) and 2,2-diphenyl-1-picrylhydrazyl (DPPH; Sigma-Aldrich, St. Louis, MO, USA). The radical scavenging activity of OBS-E against ABTS was determined using the method 
reported by Kim et al. [22]. Briefly, $200 \mu \mathrm{L}$ of ABTS working solution (molar absorptivity $\left.0.8 \mathrm{~cm}^{-1} \mathrm{M}^{-1}\right)$ was reacted with $10 \mu \mathrm{L}$ of OBS-E $(0.125-1 \mathrm{mg} / \mathrm{mL})$ for $30 \mathrm{~min}$ at RT, and the changed absorbance was measured at $734 \mathrm{~nm}$ using a microplate reader (Epoch 2; BioTek Instruments Inc., Winooski, VT, USA). The radical scavenging activity of OBS-E against DPPH was also measured using a previously reported method [22]. Ten microliters of OBS-E (0.125-1 mg/mL) was allowed to react with $200 \mu \mathrm{L}$ of DPPH working solution $(0.2 \mathrm{mM})$, and then the absorbance was measured after $30 \mathrm{~min}$ at $517 \mathrm{~nm}$ using a microplate reader. The radical scavenging activities of OBS-E against ABTS and DPPH were calculated as the half maximal inhibitory concentrations $\left(\mathrm{IC}_{50}\right)$ and compared with that of ascorbic acid (Sigma-Aldrich), used as the references.

\subsubsection{Ferric-Reducing Ability of Plasma (FRAP)}

The reducing ability of OBS-E was determined by FRAP (ferric-reducing ability of plasma) assay using the method reported by Benzie and Strain [23] with slight modifications. The solution $(200 \mu \mathrm{L})$ was incubated with $10 \mu \mathrm{L}$ of OBS-E $(0.125-1 \mathrm{mg} / \mathrm{mL})$ for $4 \mathrm{~min}$ at RT, and the FRAP value was calculated by measuring the absorbance at $593 \mathrm{~nm}$ in the reaction mixture with those of samples containing ferrous ions with known concentrations. The FRAP activity of OBS-E was expressed as mole ferrous sulfate equivalent (FSE) per gram of sample.

\subsection{In Vitro Elastase Inhibition Assay}

The in vitro elastase inhibition activity of OBS-E was determined according to the method of Sultana and Lee [24] with slight modifications. Briefly, a 20- $\mu \mathrm{L}$ sample (0.125-1 mg/mL) was mixed with $0.2 \mathrm{mM}$ Tris- $\mathrm{HCl}$ buffer $(\mathrm{pH} 8.0 ; 55 \mu \mathrm{L})$ and $0.5 \mathrm{U} / \mathrm{mL}$ porcine pancreatic elastase solution (Sigma-Aldrich). Subsequently, $125 \mu \mathrm{L}$ of $1.6 \mathrm{mM}$ $N$-succinyl-Ala-Ala-Ala- $p$-nitroanilide (STANA) was added, as a substrate for elastase, and the mixture was incubated for $20 \mathrm{~min}$ at $37^{\circ} \mathrm{C}$. The color change was measured using a microplate reader (BioTek Instruments Inc.) at $410 \mathrm{~nm}$ and expressed as an $\mathrm{IC}_{50}$ value.

\subsection{Fibroblast and Keratinocyte Cultures}

The human dermal fibroblast cell line (HDFa; American Tissue Culture Collection, Manassas, VA, USA) was maintained in fibroblast basal medium (Lonza, Verviers, Belgium) containing 2\% fetal bovine serum (FBS; Lonza), $0.1 \%$ recombinant human insulin (Lonza), $0.1 \%$ gentamicin sulfate amphotericin B (Lonza), and $0.1 \%$ recombinant human fibroblast growth factor-B (Lonza). HaCaT (human epithelial keratinocyte) cells, obtained from CLS Cell Line Service (Eppelheim, Heidelberg, Germany), were maintained in Dulbecco's modified eagle medium (DMEM) with 10\% FBS (Life Technologies, Grand Island, NY, USA) and $1 \%$ penicillin-streptomycin ( $\mathrm{P} / \mathrm{S}$, GenDEPOT, Katy, TX, USA). Both cell lines were incubated at $37{ }^{\circ} \mathrm{C}$ under air conditions of $5 \% \mathrm{CO}_{2} / 95 \%$ humidity. Cells were dissociated using trypsin-ethylenediaminetetraacetic acid (EDTA) (Welgene, Daegu, Korea) and subcultured every two to three days.

\subsection{Matrix Metalloproteinase (MMP) Inhibitory Activity of Fibroblasts}

A $200 \mu \mathrm{L}$ aliquot of HDFa cells $\left(5 \times 10^{4}\right.$ cells $\left./ \mathrm{mL}\right)$ were seeded into a 96-well plates and stabilized for $24 \mathrm{~h}$. Subsequently, the culture medium was changed with FBS-free medium containing OBS-E. After incubation for $24 \mathrm{~h}$, the culture medium was collected to quantify matrix metalloproteinase (MMP) levels, whereas adherent cells were examined using the 3-(4,5-dimethylthiazol-2-yl)-2,5-diphenyltetrazolium bromide (MTT) assay to estimate the cytotoxic effect of OBS-E. The levels of MMP-1 (R\&D Systems, Minneapolis, MN, USA) and MMP-2 (R\&D Systems) were analyzed using the enzyme-linked immunosorbent assay (ELISA) kit (R\&D Systems) according to the manufacturer's instructions, and their levels were quantified using a standard curve. 


\subsection{Hyaluronic Acid Production Activity Using Keratinocytes}

A $200-\mu \mathrm{L}$ aliquot of $\mathrm{HaCaT}$ cells $\left(1 \times 10^{5}\right.$ cells $\left./ \mathrm{mL}\right)$ were seeded into a 96-well plate. After overnight culture, the medium was replaced with FBS-free medium and cultured for further $24 \mathrm{~h}$ to eliminate the effect of FBS. After removing the culture medium, OBS-E was treated to the cells at the indicated concentrations. The culture supernatants were harvested after $24 \mathrm{~h}$ and the level of hyaluronic acid (HA) in the supernatants was determined using the ELISA kit (R\&D Systems) and the level of HA was quantified using a standard curve.

\subsection{Real-Time Polymerase Chain Reaction (PCR)}

For quantitative real-time polymerase chain reaction (qPCR), HaCaT cells treated with OBS-E at the indicated times were harvested using easy-BLUE ${ }^{\mathrm{TM}}$ (iNtRON Biotechnology, Seoul, Korea), and total RNA was extracted from the cells using the phenol extraction method. cDNA was synthesized from the total RNA using an iScript cDNA synthesis kit (BioRad, Hercules, CA, USA). qPCR was performed using TB Green ${ }^{\circledR}$ Premix Ex Taq ${ }^{\mathrm{TM}}$ (Takara, Shiga, Japan) on an AriaMx Real-time PCR System (Agilent, Santa Clara, CA, USA). The mRNA expression levels of hyaluronic acid synthase-2 (HAS2; Forward: ATTACCCAGTCCTGGCTTCG; Reverse: CCTGTGGAAGACTCAGCAGAA) and aquaporine-3 (AQP3; Forward: ACGGTGGTTTCCTCACCATC; Reverse: GGCTGTGCCTATGAACTGGT) were calculated using the Agilent AriaMx software and normalized to those of GAPDH (Forward: GTCTTCACCACCATGGAGAA; Reverse: AGGAGGCATTGCTGATGAT).

\subsection{Determination of Major Phytochemicals Using Ultra High-Performance Liquid Chromatography-Mass Spectrometry (UHPLC-MS)}

To identify the major ingredients in OBS-E, an ultra high-performance liquid chromatography (UHPLC) system (LTQ Orbitrap XL; Thermo Electron Co., Waltham, MA, USA) equipped with an ACQUITY UPLC BEH C18 column $(2.1 \times 150 \mathrm{~mm}, 1.7 \mu \mathrm{m}$; Waters Co., Milford, MA, USA) was introduced, as previously described [5]. Chromatographic separation was conducted by the mobile phase mixed with (A) water and (B) acetonitrile containing $0.1 \%$ formic acid as follow gradient program: $0 \mathrm{~min} \rightarrow 0.5 \mathrm{~min}(5 \% \mathrm{~B}), 0.5 \mathrm{~min}$ $\rightarrow 10 \mathrm{~min}(5 \% \mathrm{~B} \rightarrow 80 \% \mathrm{~B}), 10 \mathrm{~min} \rightarrow 10.1 \mathrm{~min}(80 \% \mathrm{~B} \rightarrow 100 \% \mathrm{~B}), 10.1 \mathrm{~min} \rightarrow 12 \mathrm{~min}$ (100\% B). The injection volume was $400 \mu \mathrm{L}$, and the initial mobile phase condition was equilibrated for $3 \mathrm{~min}$ to ensure the reproducibility of the analysis. The ionized source was a heated electrospray ionization (HESI) probe, and HESI was preheated at $300{ }^{\circ} \mathrm{C}$ with spray voltage of $5.0 \mathrm{kV}$. The nebulizer sheath and auxiliary gas flow rates were set at 50 and $5 \mathrm{arb}$, respectively. Mass spectrometry (MS) analysis was performed with polarity switching, and the following parameters for the MS/MS (MS ${ }^{2}$ ) scan: $m / z$ range of 100 to 1000; collisioninduced dissociation energy of $45 \%$; data-dependent scan mode. The Orbitrap analyzer was used for high-resolution mass spectra data acquisition with a mass resolving power of 30,000 , full width at half maximum at $m / z 400$. The data-dependent $\mathrm{MS}^{2}$ experiments were controlled using a menu-driven software with the Xcalibur program (Thermo Electron, Co.). All experiments were performed under automatic gain-control conditions.

\subsection{Quantification of Major Polyphenols Using High-Performance Liquid Chromatography with a} Diode Array Detector (HPLC-DAD)

For quantitative analysis of the major ingredients in OBS-E, an HPLC system (1200 series; Agilent Technologies, Inc., Palo Alto, CA, USA) coupled with a YMC-Triart C18(250 $\times 4.6 \mathrm{~mm}, 5 \mu \mathrm{m}$; YMC Co., Ltd., Kyoto, Japan) and a diode array detector (Agilent Technologies, Inc.) at a wavelength of $257 \mathrm{~nm}$ was used. The column temperature and injection volume was set at $35{ }^{\circ} \mathrm{C}$ and $20 \mu \mathrm{L}$, respectively. The gradient program for the mobile phase combined with (A) $2 \%$ formic acid/water and (B) $2 \%$ formic acid /methanol was as follows: $0 \mathrm{~min} \rightarrow 2 \mathrm{~min}(5 \% \mathrm{~B}), 2 \mathrm{~min} \rightarrow 10 \mathrm{~min}(5 \% \mathrm{~B} \rightarrow 25 \% \mathrm{~B}), 10 \mathrm{~min} \rightarrow 20 \mathrm{~min}$ $(25 \% \mathrm{~B} \rightarrow 40 \% \mathrm{~B}), 20 \mathrm{~min} \rightarrow 40 \mathrm{~min}(40 \% \mathrm{~B} \rightarrow 60 \% \mathrm{~B}), 40 \mathrm{~min} \rightarrow 45 \mathrm{~min}(60 \% \mathrm{~B} \rightarrow 100 \% \mathrm{~B})$, $45 \mathrm{~min} \rightarrow 50 \mathrm{~min}(100 \% \mathrm{~B} \rightarrow 5 \% \mathrm{~B})$. The initial mobile phase condition was equilibrated for 
$10 \mathrm{~min}$ to ensure the reproducibility of the analysis. Reference materials, such as gallic acid (CAS No. 149-91-7), luteolin 7-glucuronide (CAS No. 29741-10-4), quercetin 3-glucuronide (CAS No. 22688-79-5), and ellagic acid (CAS No. 476-66-4) were purchased from the Natural Product Institute of Science and Technology (Anseong, Korea). The quantification of the four major ingredients in OBS-E was undertaken by the calibration curves obtained from the external standard method, using five concentrations $(0.0625-0.5 \mathrm{mg} / \mathrm{mL})$, of the standard mixtures.

\subsection{Statistical Analysis}

Results were expressed as the mean \pm standard deviation (SD) of three independent experiments. Statistical differences were evaluated using one-way analysis of variance (ANOVA), and post-hoc analysis was conducted using the Tukey's test. A $p$-value of $<0.05$ was considered statistically significant. Statistical analyses were performed using PASW Statistics 18 (IBM Co., Armonk, NY, USA).

\section{Results}

\subsection{Antioxidant and Elastase Inhibition Activities}

The free radical scavenging activities of OBS-E against ABTS and DPPH are presented in Table 1. Compared with ascorbic acid (115.2 and $145.4 \mu \mathrm{g} / \mathrm{mL})$ used as the positive control (PC), OBS-E showed 2.5- and 2.3-fold higher $\mathrm{IC}_{50}$ values against ABTS and DPPH (293.0 and $332.9 \mu \mathrm{g} / \mathrm{mL}$, respectively). The reducing power of OBS-E determined using the FRAP assay was 2.84 mole FSE/g (Table 1), which was about 4.0-fold lower compared with that of ascorbic acid (11.5 mole FSE/g). With respect to the inhibition of elastase, a biomarker for wrinkle formation, OBS-E showed an $\mathrm{IC}_{50}$ value of $178.4 \mu \mathrm{g} / \mathrm{mL}$, which was 2.5-fold higher than that of the reference, ascorbic acid $(71.5 \mu \mathrm{g} / \mathrm{mL}$ ) (Table 1).

Table 1. Antioxidant and elastase inhibitory activities of Oenothera biennis sprout extract (OBS-E).

\begin{tabular}{ccccc}
\hline Sample & $\begin{array}{c}\text { ABTS } \\
\left(\mathbf{I C}_{\mathbf{5 0}}, \boldsymbol{\mu g} / \mathbf{m L}\right)\end{array}$ & $\begin{array}{c}\text { DPPH } \\
\left(\mathbf{I C}_{\mathbf{5 0}}, \boldsymbol{\mu g} / \mathbf{m L}\right)\end{array}$ & $\begin{array}{c}\text { FRAP } \\
(\text { Mole FSE/g) }\end{array}$ & $\begin{array}{c}\text { Elastase } \\
\text { Inhibition } \\
\left(\mathbf{I C}_{\mathbf{5 0}, \boldsymbol{\mu} / \mathbf{m L})}\right.\end{array}$ \\
\hline $\begin{array}{c}\text { Ascorbic acid } \\
\text { OBS-E }\end{array}$ & $115.2 \pm 0.4$ & $145.4 \pm 2.9$ & $11.5 \pm 0.3$ & $71.5 \pm 3.3$ \\
\hline
\end{tabular}

ABTS, 2,2'-azino-bis (3-ethylbenzothiazoline-6-sulfonic acid); DPPH, 2,2-diphenyl-1-picrylhydrazyl IC $_{50}$, half maximal inhibitory concentration; FRAP, ferric reducing ability of plasma; FSE, ferrous sulfate equivalent.

\subsection{Anti-Wrinkle Activity}

To elucidate whether OBS-E affected wrinkle improvement, the inhibitory activities of MMP-1 (collagenase) and MMP-2 (gelatinase) were measured using HDF cells. First, the cytotoxic effect determined using MTT assay showed that OBS-E significantly affected cell viability at doses above $200 \mu \mathrm{g} / \mathrm{mL}$ (data not shown), but it did not show any significant cytotoxicity at doses ranging from 12.5 to $100 \mu \mathrm{g} / \mathrm{mL}$ (Figure 1a). At the doses that were not cytotoxic, the production of MMP-1 was significantly decreased by treatment with OBS-E in a dose-dependent manner [ $-31.0 \%$ to $-74.5 \%$ against the negative control (NC) group] (Figure 1b). OBS-E also significantly inhibited the production of MMP-2 $(-26.9 \%$ to $-57.7 \%)$ in a dose-dependent manner (Figure 1c). In addition, the production of type I procollagen was dose-dependently increased by treatment with OBS-E $(+21.6 \%$ to $+100.9 \%)$, however, the difference was statistically significant only at doses ranging from 25 to $100 \mu \mathrm{g} / \mathrm{mL}$ (Figure 1d). 


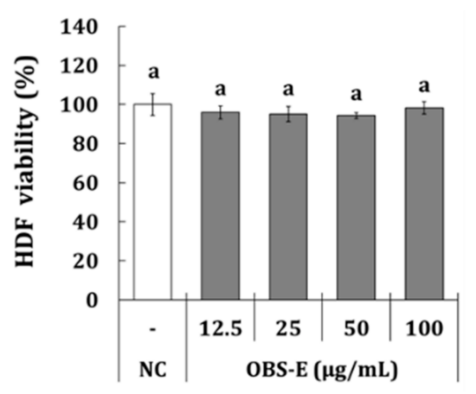

(a)

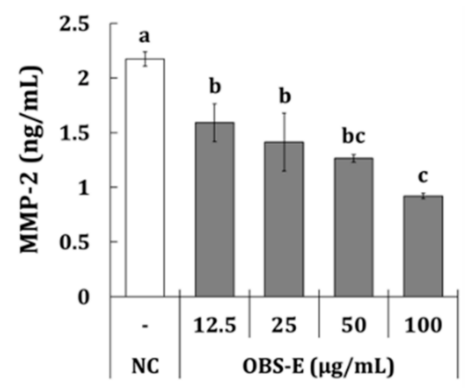

(c)

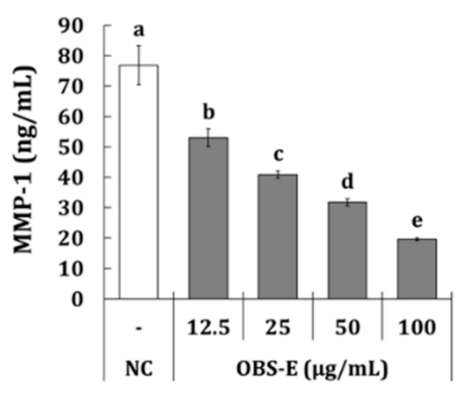

(b)

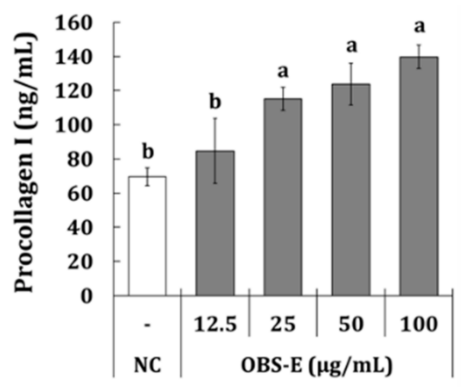

(d)

Figure 1. Anti-wrinkle activity of OBS-E in human dermal fibroblasts (HDF). (a) Cell viability, (b) MMP-1 inhibition, (c) MMP-2 inhibition, (d) procollagen type I production. Only medium was used as a negative control (NC). The different superscripts indicate significant differences among groups as analyzed using the Tukey's $t$-test $(p<0.05)$. MMP, matrix metalloproteinase.

\subsection{Moisturizing Activity}

Before measuring the effect of OBS-E on skin hydration using HaCaT keratinocytes, a MTT assay was carried out to estimate the cytotoxic effect of OBS-E. Although OBS-E led to a slightly decreased cell viability ( $-2.2 \%$ to $-11.0 \%$ against the NC group), it showed above $80 \%$ viability at all the tested concentrations compared with the NC group (Figure 2a), indicating that a serious toxic effect was not observed. As shown in Figure $2 b$, the HA content in the PC group treated with $N$-acetylglucosamine (NAG; $5 \mathrm{mg} / \mathrm{mL}$ ) was significantly higher $(+286.4 \%)$ than that in the NC group. HA production was significantly increased in the OBS-E-treated groups at the doses of 50 and $100 \mu \mathrm{g} / \mathrm{mL}(+75.4 \%$ and $+165.0 \%$, respectively), but it did not show significant differences at doses below $25 \mu \mathrm{g} / \mathrm{mL}$. The effect of OBS-E on the expression of HAS2 and AQP3 (gene coding for enzymes responsible for the moisturizing effect) was investigated using qPCR. Although the difference was not statistically significant different at doses below $25 \mu \mathrm{g} / \mathrm{mL}, H A S 2$ mRNA expression was significantly increased by OBS-E treatment at the doses of 50 and $100 \mu \mathrm{g} / \mathrm{mL}(+75.4$ and $+165.0 \%$, respectively) compared with that of the NC group (Figure $2 \mathrm{c}$ ). Furthermore, treatment with OBS-E significantly increased the expression of AQP3 mRNA at doses ranging from 25 to $100 \mu \mathrm{g} / \mathrm{mL}$ (2.19- to 3.09-fold increase against the NC) (Figure 2d). 


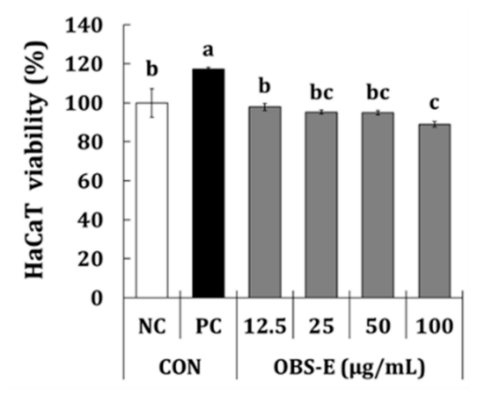

(a)

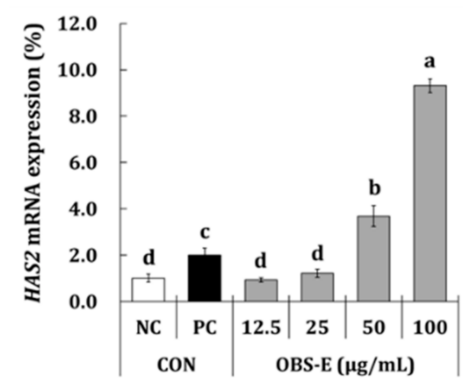

(c)

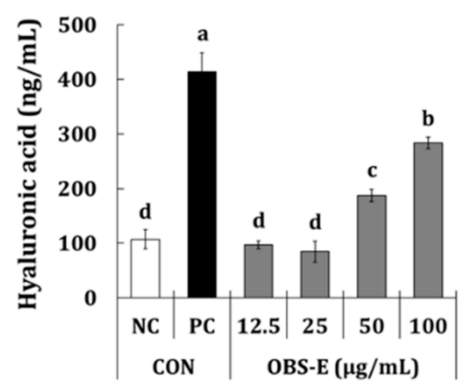

(b)

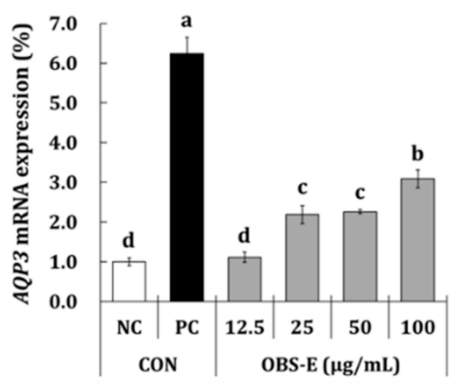

(d)

Figure 2. Skin-moisturizing activity of OBS-E in human keratinocytes (HaCaT). (a) Cell viability, (b) hyaluronic acid production, (c) HAS2 mRNA expression, (d) AQP3 mRNA expression. Medium and $N$-acetylglucosamine $(5000 \mu \mathrm{g} / \mathrm{mL})$ were used as a negative control (NC) and a positive control (PC), respectively. The different superscripts indicate significant differences among groups as analyzed using the Tukey's $t$-test $(p<0.05)$. HAS2, hyaluronic acid synthase-2; $A Q P 3$, aquaporine-3.

\subsection{Identification and Quantification of Major Components of OBS-E}

To identify the major OBS-E ingredients, OBS-E was analyzed using UHPLC coupled with ESI and $\mathrm{MS}^{2}$, and data-dependent acquisition was performed using an ion trap mass spectrometer. The MS data were manually sorted to list such information as the retention time, $m / z$ values with negative and positive modes, and $\mathrm{MS}^{2}$ fragmentation pattern, from base-peak chromatograms (Table 2). Each peak in the high-resolution MS and MS ${ }^{2}$ spectrum was identified by searching the natural-product database available online and in-house $\mathrm{MS}^{2}$ spectral library. The total ion chromatogram (TIC) of OBS-E is presented in Figure $3 \mathrm{a}$, and the MS and $\mathrm{MS}^{2}$ spectra of specific ion peaks are illustrated in Figure $3 \mathrm{~b}$. The ion peak at $1.95 \mathrm{~min}$ in TIC was confirmed as a molecular weight of $\mathrm{m} / \mathrm{z} 169.0000$ $\left([\mathrm{M}-\mathrm{H}]^{-}\right)$in the negative mode, and its $\mathrm{MS}^{2}$ product ion $(\mathrm{m} / \mathrm{z} 124.8834)$ led us to identify the presence of gallic acid. Simultaneously, three additional ion peaks $(6.68,6.96$, and $7.78 \mathrm{~min})$ were characterized by molecular weights of $\mathrm{m} / \mathrm{z} 301.1167$ $\left([\mathrm{M}-\mathrm{H}]^{-}\right), 479.0788\left([\mathrm{M}+\mathrm{H}]^{+}\right)$, and $463.0841\left([\mathrm{M}+\mathrm{H}]^{+}\right)$, respectively. They were tentatively identified as ellagic acid, quercetin 3-glucuronide (miquelianin), and luteolin 7glucuronide, respectively (Figure 3b). Their identity was confirmed by comparing our data with the mass data of commercially obtained references and published preliminary results (data not shown). Finally, these putative compounds were definitely identified based on their chromatographic fingerprint established using HPLC-DAD (Figure 4), and the results showed that OBS-E contains $28.28 \mathrm{mg} / \mathrm{g}$ gallic acid, $7.75 \mathrm{mg} / \mathrm{g}$ luteolin 7-glucuronide, $16.09 \mathrm{mg} / \mathrm{g}$ quercetin 3-glucuronide, and $18.3 \mathrm{mg} / \mathrm{g}$ ellagic acid. 
Table 2. Identification of four major ingredients in OBS-E using UHPLC-MS.

\begin{tabular}{|c|c|c|c|c|c|c|}
\hline $\begin{array}{c}\text { RT } \\
(\mathrm{min})\end{array}$ & $\begin{array}{c}\text { MS } \\
(m / z)\end{array}$ & Ionized Form & $\begin{array}{c}\text { Calculated } \\
\text { Formula }\end{array}$ & $\operatorname{MS}^{2}(m / z)$ & $\Delta \mathrm{ppm}$ & Identification \\
\hline 1.95 & 169.0000 & $\left([\mathrm{M}-\mathrm{H}]^{-}\right)$ & $\mathrm{C}_{7} \mathrm{H}_{5} \mathrm{O}_{5}$ & 124 & -1.594 & Gallic acid \\
\hline 6.68 & 301.0833 & $\left([\mathrm{M}-\mathrm{H}]^{-}\right)$ & $\mathrm{C}_{14} \mathrm{H}_{5} \mathrm{O}_{8}$ & $184,200,229,256,284$ & -1.990 & Ellagic acid \\
\hline 6.96 & 479.0788 & $\left([\mathrm{M}+\mathrm{H}]^{+}\right)$ & $\mathrm{C}_{21} \mathrm{H}_{19} \mathrm{O}_{13}$ & 303 & -1.694 & $\begin{array}{l}\text { Quercetin } \\
\text { 3-glucuronide }\end{array}$ \\
\hline 7.78 & 463.0841 & $\left([\mathrm{M}+\mathrm{H}]^{+}\right)$ & $\mathrm{C}_{21} \mathrm{H}_{19} \mathrm{O}_{12}$ & 287 & -1.656 & $\begin{array}{c}\text { Luteolin } \\
\text { 7-glucuronide }\end{array}$ \\
\hline
\end{tabular}

RT, retention time; MS/MS, tandem mass spectrometry.

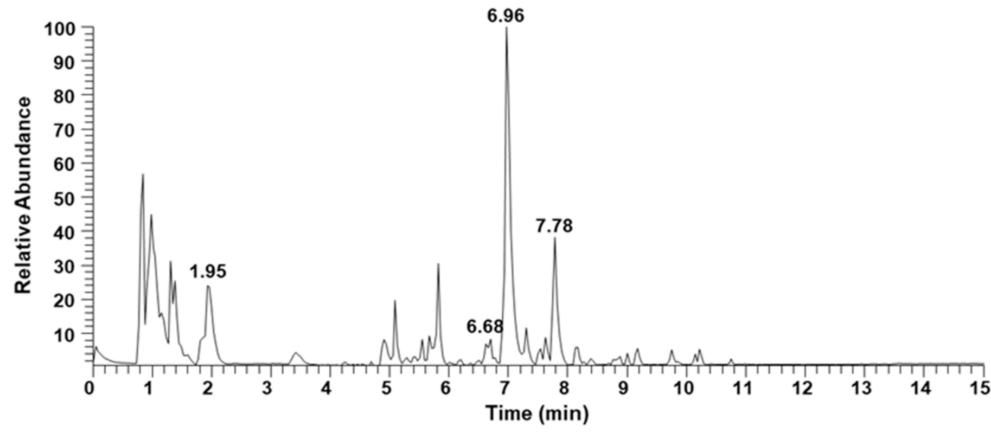

(a)
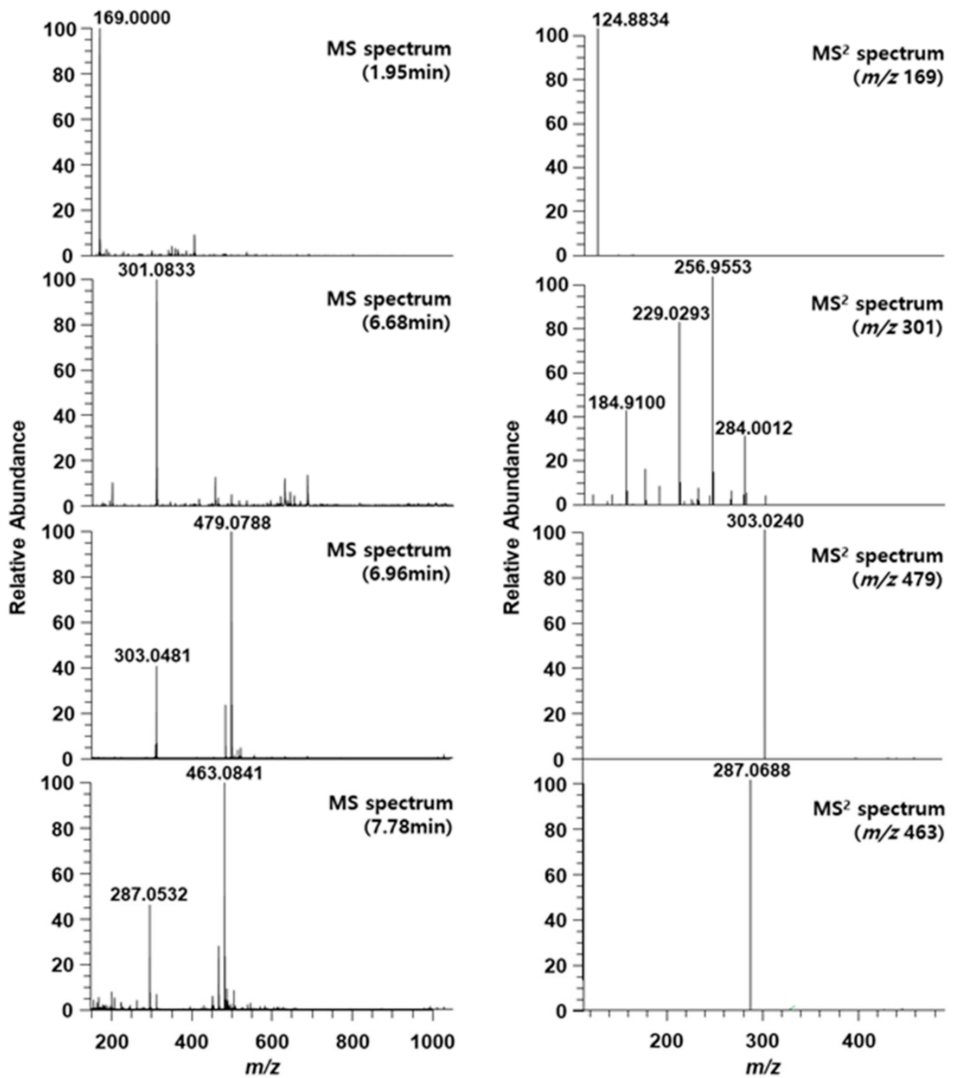

(b)

Figure 3. Ultra high-performance liquid chromatography-mass spectrometry (UHPLC-MS) chromatogram of OBS-E. (a) Total ion chromatogram. (b) MS and $\mathrm{MS}^{2}$ spectra of the peaks at $1.95 \mathrm{~min}$, $6.68 \mathrm{~min}, 6.96 \mathrm{~min}$, and $7.78 \mathrm{~min}$ on the total ion chromatogram. OBS-E was applied to the UHPLC system at a $10 \mathrm{mg} / \mathrm{mL}$ dose. 
(a)
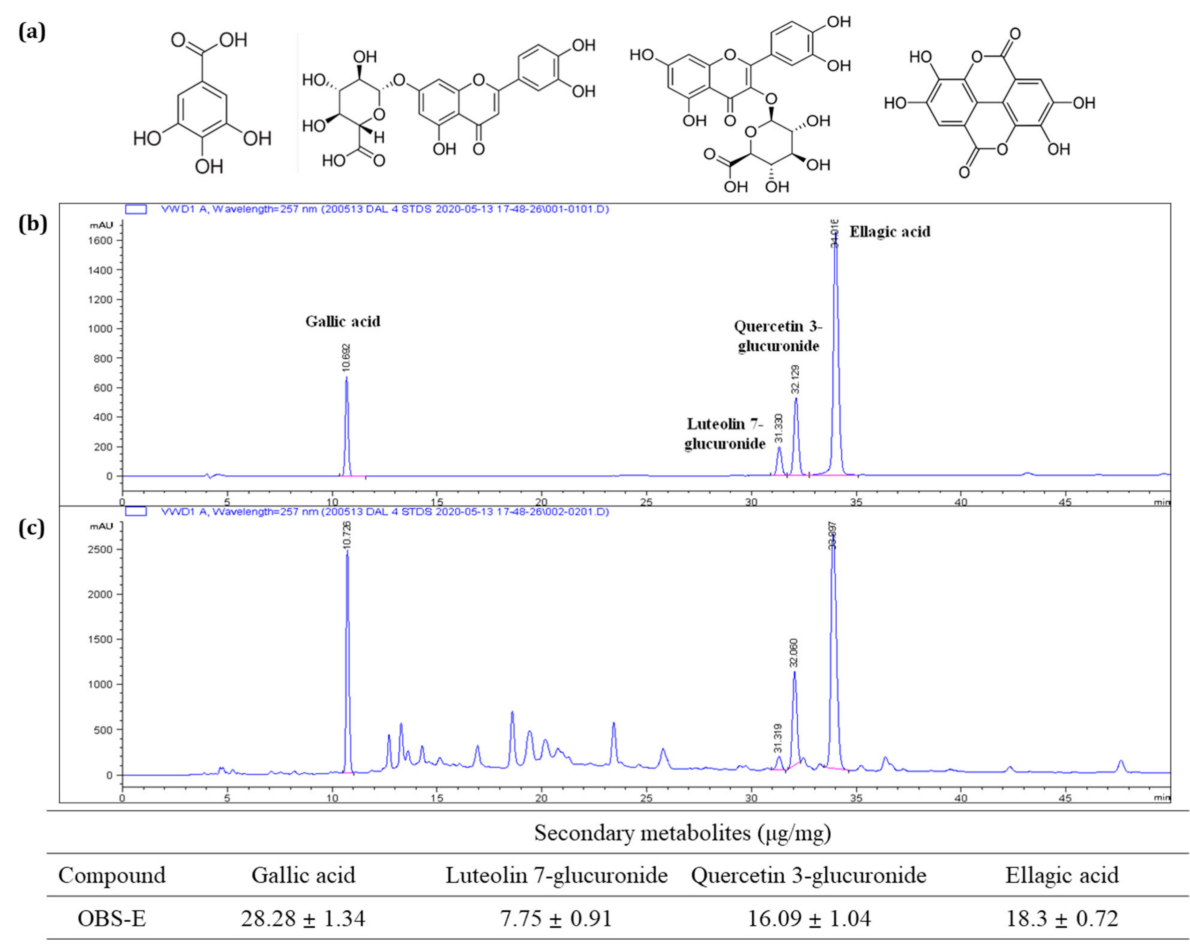

Figure 4. HPLC- ultraviolet detector (UVD) chromatogram of standard references and OBS-E and contents of major ingredients in OBS-E. (a) HPLC chromatogram of a mixture of standard references $(250 \mu \mathrm{g} / \mathrm{mL}$, each), (b) HPLC chromatogram of OBS-E $(10 \mathrm{mg} / \mathrm{mL})$, (c) chemical structure of gallic acid, luteolin 7-glucuronide, quercetin 3-glucuronide, and ellagic acid, respectively. Standard materials and OBS-E were applied to the HPLC system and detection was performed at $257 \mathrm{~nm}$.

\section{Discussion}

The skin is the largest organ in the human body and is vital for our survival, acting as the primary barrier to external attacks, such as infectious agents and physical injury, and fulfilling several important physiological roles [2,25]. As skin health is regarded as the most important facets of human health, the development of novel natural products rather than synthetic ingredients for use in the beauty industry has received increasing attention. In the present study, we aimed to investigate the potential use of OBS-E as a new nutraceutical ingredient for the enhancement of skin health. Our results showed that OBS-E has the possibility of utilization as an antioxidant agent. In spite of using the crude extract instead of a purified substance, OBS-E showed just a 2.3- to 2.5-fold lower radical scavenging activity as well as a $4.0-$ fold lower ferric reducing ability compared with ascorbic acid, which was used as a PC. This suggests that OBS-E can be considered as a candidate to be used as a natural antioxidant ingredient. Although several studies have reported the antioxidant ability of Oenothera species using whole plants [4], aerial parts [26], and roots [7], few studies have investigated the antioxidant activity of OBS. However, for clear identification regarding the antioxidative activity or mechanism of the OBS-E, it seems necessary to test antioxidant activity using the skin cells, such as fibroblasts and keratinocytes. OBS-E.

With respect to its anti-wrinkle activity, OBS-E showed just a 2.5-fold lower elastase inhibitory activity than ascorbic acid, used as PC. From the viewpoint of industrially wide use of ascorbic acid as anti-aging agents, the result suggests a possibility of use as an antiwrinkle agent using OBS-E. OBS-E also significantly decreased the levels of two types of MMP (MMP-1 and MMP-2) at 12.5 to $100 \mu \mathrm{g} / \mathrm{mL}$ doses. Because MMPs play a pivotal role in the breakdown of collagenous extracellular matrix in dermal connective tissues of the skin, inhibition or regulation of MMPs is important for healthy skin [27]. MMP-1, known as interstitial collagenase, preferentially degrades fibrillary collagens, which maintain the tensile strength of fetal membranes, whereas MMP-2, also known as gelatinase A, 
further degrades the collagen fragments formed by MMP-1 [28]. MMPs formed by intrinsic or extrinsic factors are known to mainly disintegrate the extracellular matrix, such as collagen and elastic fibers, which are structural components of the dermis, resulting in dermal inflammation, cancer metastasis, and skin aging [29]. OBS-E also induced the significant production of type I procollagen in dermal fibroblasts at doses ranging from 25 to $100 \mu \mathrm{g} / \mathrm{mL}$, suggesting that it is likely to be effective in skin hydration as well as wrinkle improvement at indicated doses. Our results are consistent with those of Kim, et al. [30], who reported that the methanol extract of $O$. laciniata induced collagen production by $38.7-113.0 \%$ at $6.25-50 \mu \mathrm{g} / \mathrm{mL}$ doses. Therefore, our results suggest that OBS-E could be a candidate anti-winkle agent, inhibiting MMPs, and facilitating procollagen synthesis.

HA is naturally synthesized via a highly controlled process involving the integral membrane enzymes known as HAS [31]. In particular, HAS2 is highly expressed in vertebrates and plays an important role in HA synthesis compared to other HAS family members, such as HAS1 and HAS3 [32]. Our results demonstrated that treating keratinocytes with OBS-E led to a significant improvement of the HA level at doses of 50 and $100 \mu \mathrm{g} / \mathrm{mL}$, which seemed to be correlated with the expression of HAS2. Furthermore, treatment with OL-E upregulates the $A Q P 3$ gene, which is another moisturizing factor that functions as a water channel transferring water, and in some cases, small solutes across the membrane in vertebrates [33,34]. Although there are several reports on the physiological activities of evening primrose extract, there are few reports on its skin moisturizing efficacy. To our knowledge, this is the first study to demonstrate that evening primrose extract could contribute to promoting skin moisturization via the upregulation of HAS2 and AQP3.

Qualitative analysis using UHPLC-MS analysis revealed the presence of four secondary metabolites in OBS-E, namely gallic acid, luteolin 7-glucuronide, quercetin 3-glucuronide, and ellagic acid, which were tentatively proposed as the bioactive constituents in OBS-E. These were further analyzed using HPLC-DAD to identify and quantify their concentrations. The results showed that the concentrations of gallic acid, luteolin 7-glucuronide, quercetin 3-glucuronide, and ellagic acid were 28.28, 7.75, 18.30, and $16.09 \mu \mathrm{g} / \mathrm{mg}$, respectively. To date, numerous secondary metabolites, such as esters, alcohols, triterpenoids, fatty acids, polyphenolic acids, lactones, flavonoids, and sterols have been discovered and isolated from the root and stem tissues of OB [21]. Nevertheless, to our knowledge, the four phytochemicals identified in this study are the first to be identified in OB sprouts. Interestingly, OBS-E has high contents of polyphenolic acids, such as gallic acid and ellagic acid (a dimer of gallic acid). In particular, there are a number of studies on the skin health effects of gallic acid, such as skin-whitening [35], anti-photoaging [36], anti-inflammatory [37], anti-psoriasis [38], and wound healing effects [39]. Therefore, we speculate that this fundamental polyphenolic acid plays a crucial role in the antioxidant, anti-wrinkle, and moisturizing activities of OBS-E. The role of gallic acid in these OBS-E activities will be fully elucidated in our further studies.

\section{Conclusions}

In the present study, we showed that the OBS-E exerts antioxidant, winkle improving, and skin-moisturizing activities and possesses high levels of polyphenolic acids, such as gallic acid and ellagic acid, and flavonoid glycosides, such as luteolin 7-glucuronide and quercetin 3-glucuronide. To the best of our knowledge, this is the first study to reveal that OBS-E may serve as a functional ingredient in anti-aging and moisturizing products, and our results might be utilized as basic data for development of skin-health products using OBS-E.

Supplementary Materials: The following are available online at https:/ / www.mdpi.com/2227-971 7/9/1/145/s1, Figure S1. (a) Test article used in this study and (b) polymerase chain reaction (PCR) amplification of test article by ITS DNA analysis. $\mathrm{M}: 1 \mathrm{~Kb}(+), 1$ : test article, N:negative control. Table S1. Genetic identification of test article by ITS DNA analysis.

Author Contributions: Data curation, W.J.K.; Formal analysis, T.H.K.; Funding acquisition, S.Y.P.; Methodology, W.J.K.; Project administration, D.K.C.; Resources, S.Y.P.; Supervision, H.K.; Validation, 
W.J.K.; Writing—original draft, T.H.K. and H.K.; Writing—review and editing, H.K. All authors have read and agreed to the published version of the manuscript.

Funding: We would like to thank Editage (www.editage.co.kr) for English language editing. This work has supported by the Ministry of Trade, Industry and Energy (MOTIE), Korea Institute for Advancement of Technology (KIAT) through the Encouragement Program for The Industries of Economic Cooperation Region.

Institutional Review Board Statement: Not applicable.

Informed Consent Statement: Not applicable.

Data Availability Statement: No new data were created or analyzed in this study. Data sharing is not applicable to this article.

Conflicts of Interest: The authors declare that there is no conflict of interest.

$\begin{array}{ll}\text { Abbreviations } \\ \text { ABTS } & \text { 2,2'-azino-bis (3-ethylbenzothiazoline-6-sulfonic acid) } \\ \text { DPPH } & \text { 2,2-diphenyl-1-picrylhydrazyl } \\ \text { MTT } & \text { 3-(4,5-dimethylthiazol-2-yl)-2,5-diphenyltetrazolium bromide } \\ \text { AQP3 } & \text { aquaporin 3 } \\ \text { FRAP } & \text { ferric reducing ability of plasma } \\ \text { IC50 } & \text { half maximal inhibitory concentration } \\ \text { HDF } & \text { human dermal fibroblast } \\ \text { HA } & \text { hyaluronic acid } \\ \text { HAS2 } & \text { hyaluronic acid synthase 2 } \\ \text { MMP } & \text { matrix metalloproteinase } \\ \text { NC } & \text { negative control } \\ \text { OB } & \text { Oenothera biennis } \\ \text { OBS } & \text { Oenothera biennis sprout } \\ \text { OBS-E } & \text { Oenothera biennis sprout extract } \\ \text { PC } & \text { positive control } \\ \text { RT } & \text { room temperature } \\ \text { TIC } & \text { total ion chromatogram }\end{array}$

\section{References}

1. Phipps, K.R.; Lee, H.Y.; Kim, H.; Jeon, B. Oral administration of a novel hydrolyzed chicken sternal cartilage extract (Biocell collagen ${ }^{\circledR}$ ) reduces UVB-induced photoaging in mice. J. Funct. Foods 2020, 68, 103870. [CrossRef]

2. Vollmer, D.L.; West, V.A.; Lephart, E.D. Enhancing skin health: By oral administration of natural compounds and minerals with implications to the dermal microbiome. Int. J. Mol. Sci. 2018, 19, 3059. [CrossRef] [PubMed]

3. Kligman, A. The future of cosmeceuticals: An interview with Albert Kligman, MD, PhD. Interview by Zoe Diana Draelos. Dermatol. Surg. 2005, 31, 890-891. [PubMed]

4. Kim, S.E.; Lee, C.M.; Kim, Y.C. Anti-melanogenic effect of Oenothera laciniata methanol extract in Melan-a cells. Toxicol. Res. 2017, 33, 55-62. [CrossRef] [PubMed]

5. Suh, M.G.; Choi, H.-S.; Cho, K.; Park, S.S.; Kim, W.J.; Suh, H.J.; Kim, H. Anti-inflammatory action of herbal medicine comprised of Scutellaria baicalensis and Chrysanthemum morifolium. Biosci. Biotechnol. Biochem. 2020, 24, 1-11. [CrossRef] [PubMed]

6. Wagner, W.L.; Hoch, P.C.; Raven, P.H. Revised classification of the Onagraceae. In Systematic Botany Monographs; Anderson, C., Ed.; American Society of Plant Taxonomists: Ann Arbor, MI, USA, 2007; Volume 83, pp. 1-240.

7. Ahmad, A.; Singh, D.K.; Fatima, K.; Tandon, S.; Luqman, S. New constituents from the roots of Oenothera biennis and their free radical scavenging and ferric reducing activity. Ind. Crops Prod. 2014, 58, 125-132. [CrossRef]

8. Kwak, C.S.; Kim, M.J.; Kim, S.G.; Park, S.; Kim, I.G.; Kang, H.S. Antioxidant and antiobesity activities of oral treatment with ethanol extract from sprout of evening primrose (Oenothera laciniata) in high fat diet-induced obese mice. J. Nutr. Health 2019, 52, 529-539. [CrossRef]

9. Yoon, W.J.; Ham, Y.M.; Yoo, B.S.; Moon, J.Y.; Koh, J.; Hyun, C.G. Oenothera laciniata inhibits lipopolysaccharide induced production of nitric oxide, prostaglandin e2, and proinflammatory cytokines in RAW264.7 macrophages. J. Biosci. Bioeng. 2009, 107, 429-438. [CrossRef]

10. Gomez-Flores, R.; Reyna-Martínez, R.; Tamez-Guerra, P.; Quintanilla-Licea, R. Antibacterial activity of Oenothera rosea (l'hér) leaf extracts. J. Adv. Med. Med. Res. 2012, 2, 396-404. [CrossRef] 
11. Pellegrina, C.D.; Padovani, G.; Mainente, F.; Zoccatelli, G.; Bissoli, G.; Mosconi, S.; Veneri, G.; Peruffo, A.; Andrighetto, G.; Rizzi, C.; et al. Anti-tumour potential of a gallic acid-containing phenolic fraction from Oenothera biennis. Cancer Lett. 2005, 226, 17-25. [CrossRef]

12. Gorlach, S.; Wagner, W.; Podsędek, A.; Sosnowska, D.; Dastych, J.; Koziołkiewicz, M. Polyphenols from evening prmrose (Oenothera paradoxa) defatted seeds induce apoptosis in human colon cancer Caco-2 cells. J. Agric. Food Chem. 2011, 59, 6985-6997. [CrossRef]

13. Frean, M.; Balkwill, K.; Gold, C.; Burt, S. The expanding distributions and invasiveness of Oenothera in southern Africa. S. Afr. J. Bot. 1997, 63, 449-458. [CrossRef]

14. Shahidi, F.; Amarowicz, R.; He, Y.; Wettasinghe, M. Antioxidant activity of phenolic extracts of evening primrose (Oenothera biennis): A preliminary study. J. Food Lipids 1997, 4, 75-86. [CrossRef]

15. Peschel, W.; Dieckmann, W.; Sonnenschein, M.; Plescher, A. High antioxidant potential of pressing residues from evening primrose in comparison to other oilseed cakes and plant antioxidants. Ind. Crops Prod. 2007, 25, 44-54. [CrossRef]

16. Montserrat-de la Paz, S.; Fernández-Arche, A.; Angel-Martín, M.; García-Giménez, M.D. The sterols isolated from evening primrose oil modulate the release of proinflammatory mediators. Phytomedicine 2012, 19, 1072-1076. [CrossRef] [PubMed]

17. Ma, R.; Chen, Q.; Li, H.; Wu, S.; Lian, M.; Jin, X.; Jiang, J. Extract of Oenothera biennis L. Stem inhibits LPS-induced inflammation by regulating MAPK and NF-KB signaling pathways. Pak. J. Pharm. Sci. 2020, 33, 1473-1481.

18. Ratz-Łyko, A.; Arct, J.; Pytkowska, K.; Majewski, S. In vivo and ex vivo evaluation of cosmetic properties of seedcakes. J. Cosmet. Laser Ther. 2015, 17, 109-115. [CrossRef] [PubMed]

19. Fecker, R.; Buda, V.; Alexa, E.; Avram, S.; Pavel, I.Z.; Muntean, D.; Cocan, I.; Watz, C.; Minda, D.; Dehelean, C.A.; et al. Phytochemical and biological screening of Oenothera biennis L. Hydroalcoholic extract. Biomolecules 2020, 10, 818. [CrossRef]

20. Timoszuk, M.; Bielawska, K.; Skrzydlewska, E. Evening primrose (Oenothera biennis) biological activity dependent on chemical composition. Antioxidants 2018, 7, 108. [CrossRef]

21. Munir, R.; Semmar, N.; Farman, M.; Ahmad, N.S. An updated review on pharmacological activities and phytochemical constituents of evening primrose (genus Oenothera). Asian Pac. J. Trop. Biomed. 2017, 7, 1046-1054. [CrossRef]

22. Kim, H.; Kim, T.H.; Jeon, B.; Bang, M.H.; Kim, W.J.; Park, J.W.; Chung, D.K. Evaluation of the physiological activity on the skin and identification of the active ingredient of leaf extract from Sanhyang Sandolbae (Pyrus ussuriensis) as a new variety. J. Korean Soc. Food Sci. Nutr. 2020, 49, 35-45. [CrossRef]

23. Benzie, I.F.F.; Strain, J.J. The ferric reducing ability of plasma (FRAP) as a measure of "antioxidant power": The FRAP assay. Anal. Biochem. 1996, 239, 70-76. [CrossRef] [PubMed]

24. Sultana, N.; Lee, N.H. Antielastase and free radical scavenging activities of compounds from the stems of Cornus kousa. Phytother. Res. 2007, 21, 1171-1176. [CrossRef] [PubMed]

25. Slominski, A.; Tobin, D.J.; Shibahara, S.; Wortsman, J. Melanin pigmentation in mammalian skin and its hormonal regulation. Physiol. Rev. 2004, 84, 1155-1228. [CrossRef]

26. Granica, S.; Czerwińska, M.E.; Piwowarski, J.P.; Ziaja, M.; Kiss, A.K. Chemical composition, antioxidative and anti-inflammatory activity of extracts prepared from aerial parts of Oenothera biennis L. and Oenothera paradoxa hudziok obtained after seeds cultivation. J. Agric. Food Chem. 2013, 61, 801-810. [CrossRef]

27. Lee, Y.R.; Noh, E.M.; Jeong, E.Y.; Yun, S.K.; Jeong, Y.J.; Kim, J.H.; Kwon, K.B.; Kim, B.S.; Lee, S.H.; Park, C.S.; et al. Cordycepin inhibits UVB-induced matrix metalloproteinase expression by suppressing the NF-kappaB pathway in human dermal fibroblasts. Exp. Mol. Med. 2009, 41, 548-554. [CrossRef]

28. Moon, H.J.; Lee, S.R.; Shim, S.N.; Jeong, S.H.; Stonik, V.A.; Rasskazov, V.A.; Zvyagintseva, T.; Lee, Y.H. Fucoidan inhibits UVB-induced MMP-1 expression in human skin fibroblasts. Biol. Pharm. Bull. 2008, 31, 284-289. [CrossRef]

29. Watt, F.M.; Fujiwara, H. Cell-extracellular matrix interactions in normal and diseased skin. Cold Spring Harbor Perspect. Biol. 2011, 3, a005124. [CrossRef]

30. Kim, S.E.; Lee, C.M.; Kim, Y.C. Anti-wrinkle efficacy of Oenothera laciniata methanol extract in human dermal fibroblasts. J. Investig. Cosmetol. 2016, 12, 197-203.

31. Necas, J.; Bartosikova, L.; Brauner, P.; Kolar, J. Hyaluronic acid (hyaluronan): A review. Vet. Med. 2008, 53, 397-411. [CrossRef]

32. Jokela, T.A.; Karna, R.; Makkonen, K.M.; Laitinen, J.T.; Tammi, R.H.; Tammi, M.I. Extracellular UDP-glucose activates P2Y14 receptor and induces signal transducer and activator of transcription 3 (STAT3) TYP705 phosphorylation and binding to hyaluronan synthase 2 (HAS2) promoter, stimulating hyaluronan synthesis of keratinocytes. J. Biol. Chem. 2014, 289 , 18569-18581. [CrossRef] [PubMed]

33. Takata, K.; Matsuzaki, T.; Tajika, Y. Aquaporins: Water channel proteins of the cell membrane. Prog. Histochem. Cytochem. 2004, 39, 1-83. [CrossRef] [PubMed]

34. Nakahigashi, K.; Kabashima, K.; Ikoma, A.; Verkman, A.S.; Miyachi, Y.; Hara-Chikuma, M. Upregulation of aquaporin-3 is involved in keratinocyte proliferation and epidermal hyperplasia. J. Investig. Dermatol. 2011, 131, 865-873. [CrossRef] [PubMed]

35. Kim, Y.J. Antimelanogenic and antioxidant properties of gallic acid. Biol. Pharm. Bull. 2007, 30, 1052-1055. [CrossRef] [PubMed]

36. Hwang, E.; Park, S.Y.; Lee, H.J.; Lee, T.Y.; Sun, Z.W.; Yi, T.H. Gallic acid regulates skin photoaging in UVB-exposed fibroblast and hairless mice. Phytother. Res. 2014, 28, 1778-1788. [CrossRef] 
37. Tsang, M.S.M.; Jiao, D.; Chan, B.C.L.; Hon, K.-L.; Leung, P.C.; Lau, C.B.S.; Wong, E.C.W.; Cheng, L.; Chan, C.K.M.; Lam, C.W.K.; et al. Anti-inflammatory activities of pentaherbs formula, berberine, gallic acid and chlorogenic acid in atopic dermatitis-like skin inflammation. Molecules 2016, 21, 519. [CrossRef]

38. Zhang, J.; Li, X.; Wei, J.; Chen, H.; Lu, Y.; Li, L.; Han, L.; Lu, C. Gallic acid inhibits the expression of keratin 16 and keratin 17 through NRF2 in psoriasis-like skin disease. Int. Immunopharmacol. 2018, 65, 84-95. [CrossRef]

39. Yang, D.J.; Moh, S.H.; Son, D.H.; You, S.; Kinyua, A.W.; Ko, C.M.; Song, M.; Yeo, J.; Choi, Y.H.; Kim, K.W. Gallic acid promotes wound healing in normal and hyperglucidic conditions. Molecules 2016, 21, 899. [CrossRef] 